\title{
Benign lymphangioma of the jejunal mesentery: an unusual cause of small bowel obstruction
}

\author{
W J Campbell, S T Irwin, J D Biggart
}

\begin{abstract}
Lymphangiomas are rare tumours of lymphatic vessels, most commonly found in children. We present the unusual case of small bowel obstruction caused by benign lymphagioma in a middle aged woman.
\end{abstract}

\section{Case report}

A 46 year old woman was admitted to hospital with small bowel obstruction. Because she had previously had a cholecystectomy, appendicectomy, and surgery for an ovarian cyst, it was presumed that her condition was caused by adhesions. When she failed to settle after three days of conservative treatment, however, laparotomy was performed.

At operation she was found to have a large multiloculated cystic mass measuring $10 \mathrm{~cm} \times 15$ $\mathrm{cm}$ in the mesentery of the small bowel, approximately $40 \mathrm{~cm}$ from the ileocaecal valve. The mesentery had undergone torsion through $180^{\circ}$ around the mass resulting in obstruction of the proximal small bowel. The torsion was reduced and the small bowel and mesenteric lesion were resected (Figure).

Histology showed this to be a benign lymphagioma of the small bowel mesentery with complete excision of the tumour. The tumour consisted of multiple cysts measuring up to $3 \mathrm{~cm}$

\footnotetext{
Departments of Surgery and Pathology, Belfast City Hospital, Belfast W J Campbell $S$ T Irwin J D Biggart

Correspondence to: $\mathrm{Mr}$ W J Campbell, Department of Surgery, The Ulster Hospital, Belfast, BT16 0RH

Accepted for publication 18 March 1991
}

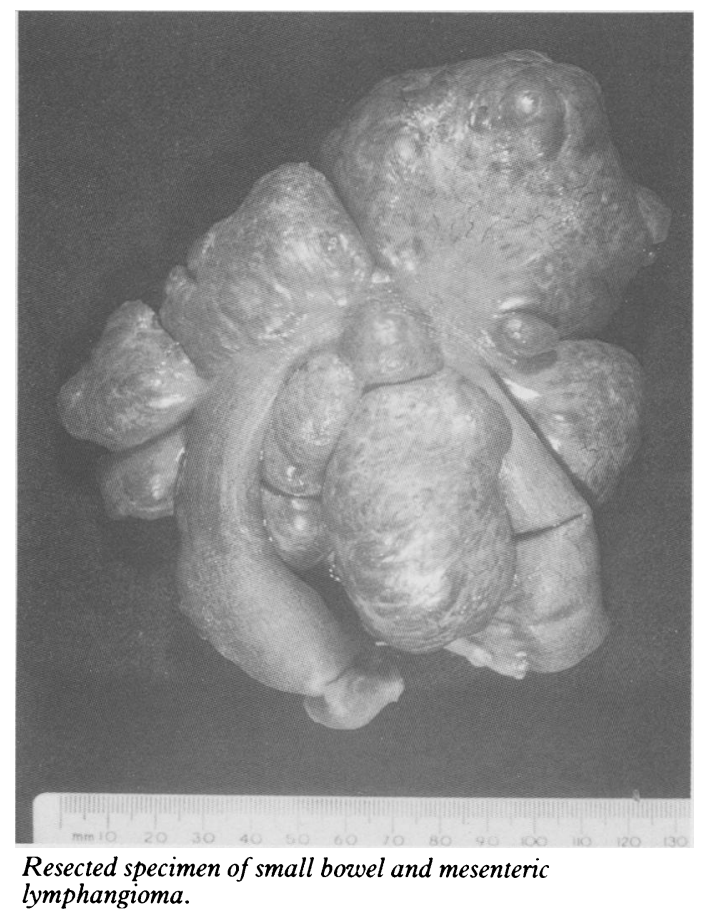

in diameter separated by fibrous or fibromuscular walls. The lymphangioma extended into the bowel wall, with increased lymphangiomatous spaces particularly prominent in the submucosa.

\section{Discussion}

Lymphangiomas are no longer considered to be truly neoplastic but rather may be the result of developmental failure of the original lymphaticovenous system. ${ }^{1}$ Three forms of lymphangioma are described:

(i) Capillary lymphangioma;

(ii) Cavernous lymphangioma;

(iii) Cystic lymphangioma. ${ }^{2}$

They consist of numerous small or large, thin walled lymphatic spaces. Approximately $50 \%$ of the lesions have an associated haemangiomatous element.

Intra-abdominal lymphangiomas are rare, accounting for approximately 1 per 100000 hospital admissions. ${ }^{2}$ They may develop in the mesentery of both the large and small bowel or less commonly in the retroperitoneal space. ${ }^{3}$

Lymphangiomas are most often found in children, $40 \%$ presenting in the first year of life and $80 \%$ before the age of 5 years. ${ }^{2+5}$ There is a male to female ratio of $3: 1 .^{6}$

In children, the most common presentation is with acute intestinal obstruction but in adults, chronic abdominal pain is more usual. Presentation with symptoms mimicking appendicitis (due to secondary infection) and with anaemia (due to haemorrhage into the mass) have been described. ${ }^{278}$ Treatment is by surgical resection and complete excision is usually curative. ${ }^{126}$

Mesenteric lymphangiomas are rare in adults. This case illustrates another unusual cause of small bowel obstruction in this age group.

1 Pang LC. Acute abdominal conditions in mesenteric lymphangioma. South Med F 1990; 83: 467-70.

2 Daniel S, Lazarevic B, Attia A. Lymphangioma of the mesentery of the jejunum: report of a case and a brief review of the literature. Am $\mathcal{F}$ Gastroenterol 1983; 78: 726-9.

3 Volker JA, Boltzer R, Hackenjos B, Dennin DE. Retroperitoneal cystic lymphangioma. Z Gastroenterol 1987; 25: 130-4.

Liessi G, Sandini F, Spaliviero B. Cystic lymphangiomas of the abdomen. CT and US findings. Radiol Med (Torino) 1989; 78: 204-9.

5 Schmidt H, Heyder N. Sonography of a mesenteric lymphangiona. Ultraschall Med 1985; 6: 331-2

6 Takiff H, Calabria R, Yin L, Stabile BE. Mesenteric cysts and intra-abdominal cystic lymphangiomas. Arch Surg 1985; 120 $1266-9$

7 Bat\% W, Hofmann von kap herr S, Koltai JI, Pistor G Mesenteric cysts in childhood. Monatsschr Kinderheilkd 1985 133: 887-90.

8 Solovei G, Alame A, Elchardus JF, et al. Mesenteric cystic lymphangioma in children. Report of a case manifested hy anaemia. Ann Pediatr (Paris) 1990; 37: 405-8. 